\title{
Activation of the Complement System in Patients with Porphyrias after Irradiation In Vivo
}

\author{
Henry W. Lim, Maureen B. Poh-Fitzpatrick, and Irma Gigli \\ Division of Dermatology, University of California, San Diego, \\ California 92103; Department of Dermatology, New York \\ University Medical Center, New York 10016; and Department of \\ Dermatology, Columbia University, New York 10032
}

bstract. Irradiation of the forearms of two patients with erythropoietic protoporphyria and one patient with porphyria cutanea tarda resulted in an in vivo activation of the complement system, as assessed by diminution of the hemolytic titers of the third component of complement by $23-57 \%$, and of the fifth component of complement (C5) by $19-47 \%$. Such treatment also generated chemotactic activity for human polymorphonuclear cells; the chemotactic activity was stable at $56^{\circ} \mathrm{C}$ and antigenically related to human $\mathrm{C} 5$. On Sephadex G-75 chromatography the chemotactic activity eluted with an apparent molecular weight of 15,000 . These in vivo results extend our previous in vitro observation of photoactivation of complement in sera from patients with erythropoietic protoporphyria and porphyria cutanea tarda, and suggest that the complement system may participate in the pathogenesis of cutaneous phototoxicity in these patients.

\section{Introduction}

Erythropoietic protoporphyria and porphyria cutanea tarda are two types of porphyria characterized by photosensitivity. In patients with erythropoietic protoporphyria, exposure to sunlight usually results in a burning, stinging sensation, which may be followed by edema and erythema (1). This is associated histologically with lysis of capillary endothelial cells, mast cell degranulation, and the appearance of polymorphonuclear cells in the dermis (2). Biochemically, ferrochelatase activity is

This work was presented in part at the Annual Meeting of the American Society for Clinical Investigation, Washington, DC, May 1982, and was published in abstract (1982. Clin. Res. 30:488A).

Address reprint requests to Dr. Lim, Division of Dermatology, H811-J, UCSD Medical Center, 225 Dickinson St., San Diego, CA 92103.

Received for publication 23 April 1984.

J. Clin. Invest.

(c) The American Society for Clinical Investigation, Inc. 0021-9738/84/12/1961/05 $\$ 1.00$

Volume 74, December 1984, 1961-1965 deficient in these patients, causing elevated levels of porphyrins, predominantly protoporphyrin, in the erythrocytes, plasma, and feces (3). Patients with porphyria cutanea tarda usually present with skin fragility, vesicles, bullae, and erosions on sun-exposed areas. Although the histologic changes in the acute phototoxic lesions in these patients have not been well studied, it is known that they have defective uroporphyrinogen decarboxylase, resulting in increased concentrations of porphyrins in the plasma, urine, and feces, with uroporphyrin as the predominant porphyrin $(4,5)$. Despite these different clinical manifestations, there are immunopathologic and electromicroscopic similarities between erythropoietic protoporphyria and porphyria cutanea tarda. In skin biopsy specimens obtained from these patients there are depositions of immunoglobulins, complement, and materials staining positively with periodic acid-Schiff reagents at the dermal-epidermal junction and the dermal capillary walls. Ultrastructurally, reduplication of basal lamina of the dermal capillaries has been observed in erythropoietic protoporphyria and porphyria cutanea tarda (6).

We have reported previously that in vitro, irradiation of sera containing exogenously added uroporphyrin, or protoporphyrin, with a light source emitting $400-410 \mathrm{~nm}$ radiation resulted in activation of the complement system, and the generation of chemotactic activity for human polymorphonuclear leukocytes $(7,8)$. Similar changes were observed when serum samples from patients with erythropoietic protoporphyria or porphyria cutanea tarda were irradiated in vitro (9). These findings suggest that complement activation might be a common denominator contributing to the development of cutaneous lesions in these two types of porphyria. To investigate whether photoactivation of complement occurred in vivo, the following studies were performed in two patients with erythropoietic protoporphyria and one patient with porphyria cutanea tarda.

\section{Methods}

Patients. The first patient was a 55-yr-old man with porphyria cutanea tarda who presented with skin fragility, vesicles, and crusting on sunexposed areas. The second and third patients were a 27- and a 34-yrold man, respectively, with erythropoietic protoporphyria. Both had a chronic history of a burning sensation with exposure to sunlight, followed by edema. The diagnosis in each patient was confirmed by 
the determination of plasma and erythrocyte porphyrin levels, as well as by the fluorescence spectra of the porphyrins, measured by previously described methods $(10,11)$. The first patient had a plasma porphyrin level of $15 \mu \mathrm{g} / \mathrm{dl}$ (normal, $<1 \mu \mathrm{g} / \mathrm{dl}$ ), which was predominantly uroporphyrin as determined by spectrophotometry, whereas his erythrocyte porphyrin level was normal. This porphyrin profile is consistent with the diagnosis of porphyria cutanea tarda (4). The plasma porphyrin levels in the second and third patients were 38 and $47 \mu \mathrm{g} / \mathrm{dl}$, respectively (normal, $<1 \mu \mathrm{g} / \mathrm{dl}$ ). The erythrocyte protoporphyrin levels in these two patients were 880 and $870 \mu \mathrm{g} / \mathrm{dl}$ of erythrocytes, respectively (normal, $<60 \mu \mathrm{g} / \mathrm{dl}$ ). By spectrophotometric measurement, the predominant porphyrin in both patients was protoporphyrin. Therefore, the porphyrin profiles of these two patients are diagnostic of erythropoietic protoporphyria (1). All three patients had received no therapy for at least 3 mo before the study.

Light source and irradiation. A cylindrical bank of 47 HO-UVA bulbs was used as the source of $400-410 \mathrm{~nm}$ light. A 5-mm Mylar filter (DuPont Co., Wilmington, DE) was used to eliminate radiation $<320 \mathrm{~nm}$. As measured with an IL700 Research Radiometer (International Light, Newburyport, MA), the output of the light source at the center of the cylinder was: $330-390 \mathrm{~nm}, 8.44 \mathrm{~mW} / \mathrm{cm}^{2}$ (PT171C sensor, WB 365 filter); $400-410 \mathrm{~nm}, 0.29 \mathrm{~mW} / \mathrm{cm}^{2}$ (PT171C sensor, NB 405 filter). The output at wavelengths shorter than $320 \mathrm{~nm}$ was $<1 \mu \mathrm{W} / \mathrm{cm}^{2}$.

After informed consent was obtained, blood was drawn from each patient to serve as the nonirradiated control sample. The entire circumferential skin surface of the left forearm was then irradiated with $0.7 \mathrm{~J} / \mathrm{cm}^{2}$ of $400-410 \mathrm{~nm}$ light. Immediately after the completion of the irradiation, blood was obtained from the antecubital vein of the irradiated forearm; in one of the patients with erythropoietic protoporphyria, blood was also obtained from the nonirradiated forearm. To minimize the exposure to light, blood was collected into test tubes wrapped in tin-foil paper, and serum was promptly separated from each sample in the cold under subdued room light. The sera were stored at $-70^{\circ} \mathrm{C}$ in aliquots until use. Parallel experiments were done with two healthy volunteers. During the irradiation, the two patients with erythropoietic protoporphyria complained of a mild burning sensation in the exposed area; clinically, a minimally perceptible erythema was noted. Neither the normal individuals nor the patient with porphyria cutanea tarda had any subjective or objective findings.

Hemolytic titration of the third and the fifth components of complement ( $C 3$ and $C 5$, respectively). ${ }^{1}$ Veronal-buffered saline, $0.15 \mathrm{M}, \mathrm{pH}$ 7.5 , containing $0.1 \%$ gelatin (GVB); GVB containing $0.15 \mathrm{mM} \mathrm{CaCl}_{2}$, and $0.5 \mathrm{mM} \mathrm{MgCl}_{2}$; and $\mathrm{GVB}$ containing $0.15 \mathrm{mM} \mathrm{CaCl}_{2}, 0.5 \mathrm{mM}$ $\mathrm{MgCl}_{2}$, and 2.5\% dextrose (DGVB++) were prepared as previously described (12). Sheep erythrocytes were sensitized with rabbit antisheep hemolysin (erythrocytes coated with antibody [EA]). EACī were prepared by mixing EA with human first component of complement (Cî), diluted to provide $\mathbf{4 0 0}$ hemolytic sites per cell. After incubation at $30^{\circ} \mathrm{C}$ for $30 \mathrm{~min}$ and at $4^{\circ} \mathrm{C}$ for $15 \mathrm{~min}$ the cells were washed in DGVB++ (13). EACī $4 \mathrm{~b}$ were prepared by incubating EACī, $1 \times 10^{9} /$ $\mathrm{ml}$, with human fourth component of complement to provide $\mathbf{4 0 0}$ hemolytic sites per cell. The mixture was incubated at $4^{\circ} \mathrm{C}$ for $30 \mathrm{~min}$ (14), the cells were washed, resuspended in DGVB++, and stored in

1. Abbreviations used in this paper: $\mathrm{C} \overline{1}, \mathrm{C} 3$, and $\mathrm{C} 5$, first, third, and fifth components of complement, respectively; DGVB++, GVB containing $0.15 \mathrm{mM} \mathrm{CaCl}, 0.5 \mathrm{mM} \mathrm{MgCl}$, and $2.5 \%$ dextrose; EA, erythrocytes coated with antibody; GVB, veronal-buffered saline, 0.15 $\mathrm{M}$, containing $0.1 \%$ gelatin. the same buffer with penicillin and streptomycin. These EACī $4 \mathrm{~b}$ cells were used to measure the hemolytic titers of $\mathrm{C} 3$ and $\mathrm{C} 5$ of the serum samples (7).

Chemotaxis of polymorphonuclear cells. Polymorphonuclear cells were obtained from venous blood of healthy adult donors by a previously described method (15). In brief, polymorphonuclear cells were isolated by dextran-sedimentation technique and suspended in phosphate-buffered saline, $\mathrm{pH} 7.4$, supplemented with $0.6 \mathrm{mM} \mathrm{CaCl}$, $1.0 \mathrm{mM} \mathrm{MgCl}$, and $2.0 \%$ of bovine serum albumin (wt/vol). Cell suspensions contained $\sim 85 \%$ polymorphonuclear cells. Random motility and directed migration (chemotaxis) of these cells were assessed by a modification of the leading front method of Zigmond and Hirsch $(7,15,16)$. Aliquots $(0.8 \mathrm{ml})$ of leukocyte suspensions, containing 2.5 $\times 10^{6}$ polymorphonuclear cells $/ \mathrm{ml}$, were added to the upper compartments of modified Boyden chambers (Nucleopore Corp., Pleasanton, CA); buffer, or serum samples, at a final dilution of $2 \%$, was placed in the lower compartments. The upper and lower compartments were separated by nitrate cellulose micropore filters (Sartorius Filters, Inc., San Francisco, CA) with $3 \mu \mathrm{m}$ pore size. The chambers containing cells and chemoattractants were incubated at $37^{\circ} \mathrm{C}$ for $35 \mathrm{~min}$. The filters were then removed, fixed in methanol, stained with hematoxylin, dehydrated in ethanol, and cleared in xylene. The response of polymorphonuclear cells, either to buffer alone (random motility), or to chemotactic stimuli, was measured as the distance that the leading front of cells migrated into the filters (micrometers per 35 minutes). This was performed by microscopic examination with a $45 \times$ objective lens, and the distance from the top of the filter to the furthest plane of focus that contained at least two cells in focus was measured. For each experiment, duplicate chambers were used, and 10 fields were examined per filter. Goat anti-human C3 and anti-human C5 antibodies used in some of the experiments, were obtained from Atlantic Antibodies (Westbrooke, ME), and Meloy Laboratories Inc.; (Springfield, VA), respectively.

Molecular-sieve chromatography. A $0.8 \times 100 \mathrm{~cm}$ calibrated column of Sephadex G75 (Pharmacia Fine Chemicals, Piscataway, NJ) was used to characterize further the chemotactic activity generated. The column was calibrated using ovalbumin, chymotrypsinogen $A$, and cytochrome C (Pharmacia Fine Chemicals, and Sigma Chemical Co., St. Louis, MO) as molecular weight markers. $1 \mathrm{ml}$ of the serum samples obtained after the irradiation was applied to the column, and

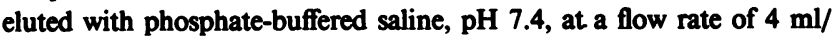
h. 1.5-ml fractions were collected, and assays for chemotactic activity were performed at a final concentration of one fifth. As a control, column chromatography of $1.0 \mathrm{ml}$ of serum treated with zymosan, a known activator of complement, was similarly performed, and the chemotactic activity in fractions collected was assayed.

\section{Results}

Effect of irradiation in vivo on the hemolytic activities of C3 and C5. Exposure to $0.7 \mathrm{~J} / \mathrm{cm}^{2}$ of $400-410 \mathrm{~nm}$ light of the forearms of patients with erythropoietic protoporphyria and porphyria cutanea tarda resulted in the diminution of the hemolytic titers of $\mathrm{C} 3$ and $\mathrm{C} 5$, as compared with the titers measured in the sera of the same patients before irradiation (Fig. 1). The decrease in titers ranged from 23 to $57 \%$ for $\mathrm{C} 3$, and from 19 to $47 \%$ for C5. In contrast, similar irradiation of healthy individuals resulted in a decrease of only $4-8 \%$ of C3 


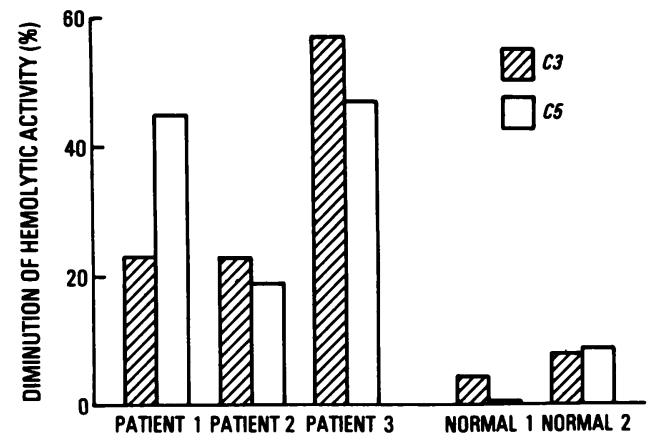

Figure 1. Diminution of hemolytic titers of $\mathrm{C} 3$ and $\mathrm{C} 5$ in sera obtained after irradiation. The results are expressed as percentage decrease of the hemolytic titers; serum obtained from the same individual before the irradiation was used as the control.

hemolytic activity, and $0-9 \%$ of C5 activity. In the serum obtained from the contralateral, nonirradiated forearm of a patient with erythropoietic protoporphyria at the completion of the irradiation, no alteration in the hemolytic titers of $\mathrm{C} 3$ and C5 was observed (data not shown).

Generation of chemotactic activity in vivo. To evaluate if the decrease in hemolytic titers of $\mathrm{C} 3$ and $\mathrm{C} 5$ after irradiation was associated with the generation of biologically active complement cleavage products, chemotactic activity for human polymorphonuclear cells was measured in the sera of the patients. Although no significant chemotactic activity was detectable in sera obtained before the irradiation, in all three patients significant chemotactic activity $(P<0.02)$ was observed after the irradiation (Fig. 2). In vivo irradiation of the forearms of healthy subjects did not result in generation of chemotactic activity. Similarly, no chemotactic activity was detectable in sera obtained from the nonirradiated forearm of one of the patients.

Characterization of the chemotactic activity. The chemotactic activity generated upon in vivo irradiation in these patients was characterized in the following experiments. Serum samples were treated with antiserum to human C3 or C5, or were incubated at $56^{\circ} \mathrm{C}$ for $30 \mathrm{~min}$; the chemotactic activity in these samples was then assayed. As shown in Table I, the chemotactic activity was markedly suppressed when the serum obtained after irradiation was treated with antiserum to human

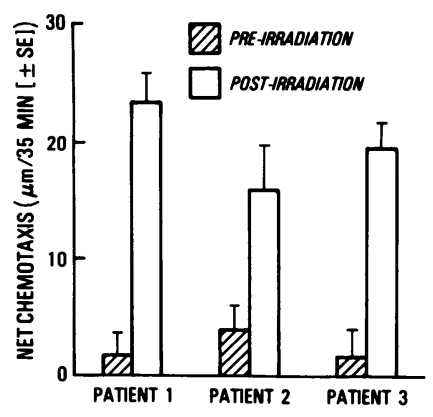

Figure 2. Generation of chemotactic activity in sera from patients, expressed as net chemotaxis (directed migration minus random migration). In every patient, there was significant chemotactic activity generated after irradiation $(P$ vs. pre-irradiation value, $<0.02$ ).
Table I. Properties of Chemotactic Activity Generated after Irradiation In Vivo*

\begin{tabular}{lc}
\hline Stimulus & Chemotaxis \\
\hline & $\mu \mathrm{m} / 35 \mathrm{~min} \pm S E$ \\
Pre-irradiation & $85.5 \pm 1.9$ \\
Post-irradiation & $103.2 \pm 1.7 \ddagger$ \\
Post-irradiation + anti-C3 & $101.5 \pm 1.7 \ddagger$ \\
Post-irradiation + anti-C5 & $82.9 \pm 1.7$ \\
Post-irradiation $\rightarrow 56^{\circ} \mathrm{C}, 30 \mathrm{~min}$ & $103.2 \pm 2.3 \ddagger$ \\
Buffer & $83.8 \pm 1.6$
\end{tabular}

* Data from a representative patient are shown.

$\ddagger P$ vs. buffer value, $<0.001$ ( $t$ test).

C5. The chemotactic activity was not altered when another aliquot of the same serum was incubated with antibody to human $\mathrm{C} 3$, or subjected to heating at $56^{\circ} \mathrm{C}$ for $30 \mathrm{~min}$.

To investigate further the physicochemical characteristics of the chemotactic activity, molecular-sieve chromatography was performed. The chemotactic activity from the serum samples obtained after irradiation from the patients eluted at the same position as that from zymosan-activated serum, corresponding to an apparent molecular weight of 15,000 (Fig. 3). These data further indicate that upon in vivo irradiation of the forearms of patients with erythropoietic protoporphyria and with porphyria cutanea tarda, chemotactic peptides were generated, which probably represented cleavage products of $\mathrm{C} 5$.

\section{Discussion}

Participation of the complement system in the pathogenesis of cutaneous lesions in patients with porphyrias is supported by

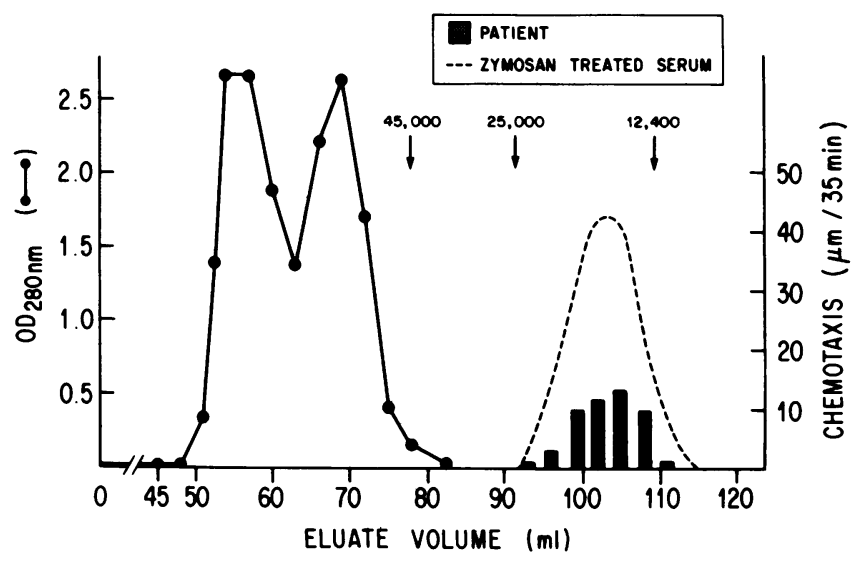

Figure 3. Elution profile of serum from a representative patient after irradiation in vivo. The molecular weight markers used were ovalbu$\min (45,000 \mathrm{~mol} \mathrm{wt})$, chymotrypsinogen $A(25,000 \mathrm{~mol} \mathrm{wt})$, and cytochrome $C(12,400 \mathrm{~mol} w t)$. Results are expressed as net chemotaxis. Chemotactic activity in patient's serum eluted with an apparent molecular weight of 15,000 , which is similar to the elution profile of zymosan-activated serum. 
several observations. Using uroporphyrin and protoporphyrin as prototypes of endogenous phototoxic agents, we previously demonstrated that in vitro irradiation of sera containing one of these phototoxic agents with the appropriate light source resulted in activation of the complement system, with a concomitant appearance of complement cleavage products and generation of chemotactic activity for human polymorphonuclear leukocytes $(6,7)$. Similar findings were observed when sera from asymptomatic patients with erythropoietic protoporphyria and porphyria cutanea tarda were irradiated in vitro (9). The acute phototoxic changes in patients with erythropoietic protoporphyria consists of a burning sensation, cutaneous erythema and edema, mast cell degranulation, and the appearance of polymorphonuclear cells in the dermis $(1,2)$. These clinical and histologic alterations are consistent with those mediated by the cleavage products of complement, C3a and C5a (17). In addition, it has been demonstrated that immunoglobulins and complement component are deposited in the dermal-epidermal junction and dermal blood vessel walls of the involved skin of patients with erythropoietic protoporphyria and porphyria cutanea tarda (6).

In guinea pigs, the clinical appearance of phototoxic lesions induced by demethychlortetracycline, a phototoxic agent, was markedly suppressed in animals that had been treated with cobra venom factor, an agent that resulted in $95 \%$ depletion of $\mathrm{C} 3$ activity and $60 \%$ depletion of C5 (18). These results were further corroborated by studies using the alteration in vascular permeability as the means to quantify the phototoxic response. As assessed by the extravasation of intravenously injected ${ }^{125}$ I-bovine serum albumin, we have demonstrated that in guinea pigs, the phototoxic response induced by hematoporphyrin was suppressed in decomplemented animals, neutropenic animals, and at sites that had been pretreated with compound $48 / 80$, a known degranulator of mast cells $(19,20)$. The above findings indicate that an intact complement system, along with neutrophils and mast cells, is required for the full development of phototoxic lesions induced by demethylchlortetracycline and hematoporphyrin.

In the present study, the in vivo relevance of our previous in vitro findings to human disease was examined. Forearms of patients with erythropoietic protoporphyria and porphyria cutanea tarda were irradiated with $0.7 \mathrm{~J} / \mathrm{cm}^{2}$ of $400-410 \mathrm{~nm}$ radiation. At sea level, with sun directly overhead, the solar irradiance is $\sim 1,100 \mu \mathrm{W} / \mathrm{cm}^{2}$ at $400-410 \mathrm{~nm}$ range (21); therefore, the irradiance dose used in this study corresponds to $\sim 11$ min of sun exposure. Such treatment resulted in a decrease of the hemolytic titers of $\mathrm{C} 3$ and C5 (Fig. 1), which was associated with the generation of chemotactic activity for human polymorphonuclear leukocytes (Fig. 2). Further characterization of the chemotactic activity revealed that it was stable at $56^{\circ} \mathrm{C}$ and inhibitable by antiserum to human $\mathrm{C} 5$ but not by antiserum to human $\mathrm{C} 3$ (Table I). These properties are consistent with the known characteristics of the C5-derived chemotactic peptides (17). This was corroborated by the results obtained from molecular-sieve chematography. Application of serum samples obtained from the irradiated forearms of the patients eluted a single peak of chemotactic activity with a molecular weight of $\sim 15,000$ (Fig. 3). This elution profile is similar to that of serum treated with zymosan, a known generator of C5a. These data indicate that the chemotactic activity generated was derived from $\mathrm{C} 5$, and most probably represents C5a or C5a-des arg.

Although the histologic and ultrastructural changes in acute phototoxic lesions of patients with porphyria cutanea tarda have not been well studied, such changes have been investigated in patients with erythropoietic protoporphyria. In this latter group, lysis of dermal capillary endothelial cells was noted $2.5 \mathrm{~h}$ after exposure to light sources emitting 400-410 $\mathrm{nm}$ radiation (2). By the use of erythrocytes as a model, it has been demonstrated that in the presence of oxygen, photoexcitation of protoporphyrin resulted in the generation of lipid peroxides, causing damage of cell membrane and hemolysis (22). In other studies, it was reported that endothelial cell damage could be induced in vitro by polymorphonuclear cells stimulated with serum-treated zymosan or phorbol myristate acetate $(23,24)$. The injury was mediated primarily by neutral proteases and hydrogen peroxide generated from activated polymorphonuclear leukocytes. In rats, systemic activation of complement by cobra venom factor results in aggregation of leukocytes and destruction of endothelial cells in interstitial pulmonary capillaries; this cell damage was prevented by pretreatment with dimethyl sulfoxide, a potent scavenger of hydroxyl radicals, indicating that tissue injury that depends upon complement and neutrophils may be related to generation of hydroxyl radicals by stimulated neutrophils (25). Therefore, it is possible that in patients with erythropoietic protoporphyria and porphyria cutanea tarda, upon exposure to $400-410 \mathrm{~nm}$ light, the peroxides generated directly by photoexcitation of porphyrin molecules, and those generated from polymorphonuclear leukocytes secondary to the photoactivation of the complement system, may act synergistically to contribute to the development of cutaneous lesions.

Patients with erythropoietic protoporphyria and those with porphyria cutanea tarda have similar immunopathologic and electromicroscopic findings in their skin (6). The alteration in their complement profile upon irradiation, as observed in the present in vivo studies and in the previous in vitro studies (9), is also qualitatively similar. However, they have different clinical manifestations $(1,4)$. Patients with erythropoietic protoporphyria complain of burning sensations when exposed to sunlight, which are often followed by the appearance of erythema and edema. Patients with porphyria cutanea tarda present with skin fragility, vesicles, erosions, hypertrichosis, and hyperpigmentation. The predominant porphyrin in patients with erythropoietic protoporphyria is protoporphyrin, a hydrophobic, dicarboxylic tetrapyrrole, whereas in patients with porphyria cutanea tarda, it is uroporphyrin, a hydrophilic, octacarboxylic molecule. Whether the differences in the phys- 
icochemical properties of these two tetrapyrrolic porphyrins, both phototoxic, account for the different clinical manifestations of these two types of porphyria remains to be elucidated.

\section{Acknowledgments}

The authors acknowledge Mr. B. Weintraub for technical assistance, and Ms. J. Cleary for typing the manuscript.

This work was supported by grants AM01165 (Clinical Investigator Award to Dr. Lim), AI20476, and AI20067 from the National Institutes of Health, and by a grant from the Irma T. Hirschl Trust (to Dr. Lim).

\section{References}

1. DeLeo, V. A., M. B. Poh-Fitzpatrick, M. M. Matthews-Roth, and L. C. Harber. 1976. Erythropoietic protoporphyria. Am. J. Med. 60:8-22.

2. Schnait, F. G., K. Wolff, and K. Konrad. 1975. Erythropoietic protoporphyria-submicroscopic events during the acute photosensitivity flare. Br. J. Dermatol. 92:545-557.

3. Sassa, S., G. L. Zalar, M. B. Poh-Fitzpatrick, K. E. Anderson, and A. Kappas. 1982. Studies in porphyria. Functional evidence for a partial deficiency of ferrochelatase activity in mitogen-stimulated lymphocytes from patients with erythropoietic protoporphyria. J. Clin. Invest. 69:809-815.

4. Grossman, M. E., D. R. Bickers, M. B. Poh-Fitzpatrick, V. A. Deleo, and L. C. Harber. 1979. Porphyria cutanea tarda: clinical features and laboratory findings in 40 patients. Am. J. Med. 67:277286.

5. Kushner, J. P., A. J. Barbuto, and G. R. Lee. 1976. An inherited enzymatic defect in porphyria cutanea tarda. Decreased uroporphyrinogen decarboxylase activity. J. Clin. Invest. 58:1089-1097.

6. Epstein, J. H., D. L. Tuffanelli, and W. L. Epstein. 1973. Cutaneous changes in the porphyrias. A microscopic study. Arch. Dermatol. 197:689-698.

7. Lim, H. W., H. D. Perez, I. M. Goldstein, and I. Gigli. 1981. Complement-derived chemotactic activity is generated in human serum containing uroporphyrin after irradiation with $\mathbf{4 0 5} \mathrm{nm}$ light. J. Clin. Invest. 67:1072-1077.

8. Lim, H. W., and I. Gigli. 1981. Role of complement in porphyrin-induced photosensitivity. J. Invest. Dermatol. 76:4-9.

9. Lim, H. W., H. D. Perez, M. B. Poh-Fitzpatrick, I. M. Goldstein, and I. Gigli. 1981. Generation of chemotactic activity in serum from patients with erythropoietic protoporphyria and porphyria cutanea tarda. N. Engl. J. Med. 304:212-216.

10. Poh-Fitzpatrick, M. B., and V. A. DeLeo. 1977. Rate of plasma porphyrin disappearance in fluorescent vs red incadescent light exposure. J. Invest. Dermatol. 69:510-512.
11. Poh-Fitzpatrick, M. B., and A. A. Lamola. 1976. Direct spectrofluorometry of diluted erythrocytes and plasma: a rapid diagnostic method in primary and secondary porphyrinemias. J. Lab. Clin. Med. 87:362-370.

12. Nelson, R. A., J. Jenson, I. Gigli, and N. Tamura. 1966. Methods for the separation, purification and measurement of nine components of hemolytic complement in guinea pig serum. Immunochemistry. 3:111-135.

13. Ruddy, S., and K. F. Austen. 1967. A stoichiometric assay for the fourth component of complement in whole human serum using $\mathrm{EAC}^{\prime} 1 \mathrm{a}^{\mathrm{GP}}$ and functionally pure human second component. J. Immunol. 99:1162-1172.

14. Ferreira, A., V. Nussenzweig, and I. Gigli. 1978. Structural and functional differences between the H-2 controlled Ss and Slp proteins. J. Exp. Med. 148:1186-1197.

15. Perez, H. D., M. Lipton, and I. M. Goldstein. 1978. A specific inhibitor of complement (C5)-derived chemotactic activity in serum from patients with systemic lupus erythematosus. J. Clin. Invest. 62:29-38.

16. Zigmond, S. H., and J. G. Hirsch. 1973. Leukocyte locomotion and chemotaxis. New methods for evaluation and demonstration of a cell-derived chemotactic factor. J. Exp. Med. 137:387-410.

17. Hugli, T. E. 1981. The structural basis for anaphylatoxin and chemotactic functions of $\mathrm{C} 3 \mathrm{a}, \mathrm{C} 4 \mathrm{a}$, and $\mathrm{C} 5 \mathrm{a}$. CRC Crit. Rev. Immunol. 1:321-366.

18. Lim, H. W., H. Novotny, and I. Gigli. 1983. Role of complement and polymorphonuclear cells in demethylchlortetracycline-induced phototoxicity in guinea pigs. Inhibition by decomplementation in vivo. J. Clin. Invest. 71:1326-1335.

19. Kamide, R., I. Gigli, and H. W. Lim. 1984. Participation of mast cells in the immediate phase of hematoporphyrin-induced phototoxicity. J. Invest. Dermatol. 82:485-490.

20. Lim, H. W., M. Hagan, and I. Gigli. 1984. Hematoporphyrininduced phototoxicity: role of mast cells, complement, and neutrophils. Clin. Res. 32:598A. (Abstr.)

21. Stair, R. 1969. Measurement of natural ultraviolet radiation. Historical and general introduction. In The Biological Effects of Ultraviolet Radiation (with Emphasis on Skin). F. Urbach, editor. Pergamon Press, Ltd., Oxford. 377-390.

22. Goldstein, B. D., and L. C. Harber. 1972. Erythropoietic protoporphyria: lipid peroxidation and red cell membrane damage associated with photohemolysis. J. Clin. Invest. 51:892-902.

23. Harlan, J. M., P. D. Killen, L. A. Harker, G. E. Striker, and D. G. Wright. 1981. Neutrophil-mediated endothelial injury in vitro. Mechanism of cell detachment. J. Clin. Invest. 68:1394-1403.

24. Weiss, S. J., J. Young, A. F. Lobuglio, A. Slivka, and N. F. Nimeh. 1981. Role of hydrogen peroxide in neutrophil-mediated destruction of cultured endothelial cells. J. Clin. Invest. 68:714-721.

25. Ward, P. A., G. O. Till, R. Kunkel, and C. Beauchamp. 1983. Evidence for role of hydroxyl radical in complement and neutrophildependent tissue injury. J. Clin. Invest. 72:789-801. 